\title{
Metode Estimasi Suhu Minyak pada Transformator Tenaga melalui Pengukuran Suhu Body Berbasis IoT
}

\author{
Rizal Alfa Rizki ${ }^{1}$, Dista Yoel Tadeus ${ }^{2}$, Fakhruddin Mangkusasmito ${ }^{2}$, Heru Winarno ${ }^{1}$, Eko Ariyanto ${ }^{1}$ \\ ${ }^{1}$ STr.Teknik Listrik Industri, Sekolah Vokasi Undip, Semarang, Indonesia \\ ${ }^{2}$ STr. Teknologi Rekayasa Otomasi, Sekolah Vokasi Undip, Semarang, Indonesia Komputer Indonesia, \\ distayoel@gmail.com, fakhm17@lecturer.undip.ac.id
}

Diterima 14 Oktober 2020

Disetujui 11 November 2020

\begin{abstract}
Oil cooled power transformer has important role in the electricity distribution system. Its windings were immersed in oil as an insulating medium and also as a cooler. This oil would be heated up due to several things, the most significant was heat generated by winding's power loss. The monitoring of oil temperature on the transformer was always done routinely every day to maintain its performance and health condition. Io $T$ based measurements could improved efficiency and minimized manpower resources. To realize this the indirect nondestructive measurement method was proposed to estimate transformator's temperature oil. It will corellate the oil temperature and body temperature through a constant calibration factor derived from calculations. Conducted experiment applied to specific existing transformator and followed by calculations resulted a calibration factor $=1.7749$. The smallest average of estimated temperature error was lied in the range of 40 90 degrees Celcius.
\end{abstract}

Index Terms- Oil Temperature, Transformer, Nondestructive Measurement

\section{PENDAhUluan}

Dalam sistem transmisi, gardu induk merupakan komponen pokok dalam proses penyaluran tenaga listrik. Salah satu alat yang penting dalam gardu induk adalah transformator tenaga [1]. Pada sistem tegangan ekstra tinggi $(500 \mathrm{kV})$ di Indonesia menggunakan Interbus Transformer (IBT) untuk menyalurkan listrik ke sistem tegangan tinggi $(150 \mathrm{kV})$ yang kemudian ditransmisikan atau ditransformasikan lagi untuk didistribusikan ke pelanggan [2], [3]. Salah satu bagian utama dalam transformator tenaga adalah minyak transformator. Seluruh bagian belitan-belitan dan inti transformator tenaga direndam dalam minyak transformator, terutama transformator tenaga yang berkapasitas besar. Hal itu dikarenakan minyak transformator mempunyai sifat sebagai isolasi dan media pemindah panas, sehingga minyak transformator tersebut berfungsi sebagai media pendingin dan isolasi, juga sebagai penahan korosi. Minyak pada transformator sering kali memanas dikarenakan beberapa hal salah satunya yang paling signifikan adalah karena panasnya belitan [4], [5]. Oleh karena itu pengawasan atau pemantauan suhu minyak pada transformator selalu dilakukan rutin setiap harinya. Pemantauan suhu minyak dilakukan pada semua transformator di gardu induk, artinya akan sangat banyak transformator yang perlu dipantau pada GITET (Gardu Induk Tegangan Ekstra Tinggi) karena 1 bay IBT saja terdiri dari 3 transformator. Ini mengakibatkan pembacaan suhu minyak kurang efisien dan tidak dapat terpantau setiap waktu dengan mudah. Untuk mengatasi persoalan tersebut, diperlukan suatu sistem pengukuran suhu minyak trafo berbasis IoT yang dapat diakses dari ruang kontrol sehingga pekerjaan pemeliharaan transformator dapat menjadi lebih efektif dan efisien dalam hal waktu dan tenaga. Namun sistem pengukuran suhu minyak trafo berbasis IoT tersebut menimbulkan persoalan lain, yaitu sulitnya menempatkan sensor suhu di dalam minyak transformator existing yang akan mengarah pada destructive measurement [6],[7] karena dibutuhkan modifikasi mekanis pada badan transformator untuk memasukkan sensor. Hal ini tentu tidak dapat dilakukan dengan mudah dan berisiko tinggi. Artikel ini memaparkan suatu metode estimasi suhu minyak transformator dengan cara non-destructive yang lebih mudah dan aman yaitu melalui pengukuran suhu badan trafo. Data akuisisi suhu badan trafo digunakan untuk menyusun model termal matematis lalu dilanjutkan dengan perhitungan faktor kalibrasi, sehingga suhu minyak transformator dapat ditentukan secara langsung melalui suhu badan transformator. 


\section{METODOLOGI}

A. Blok Diagram

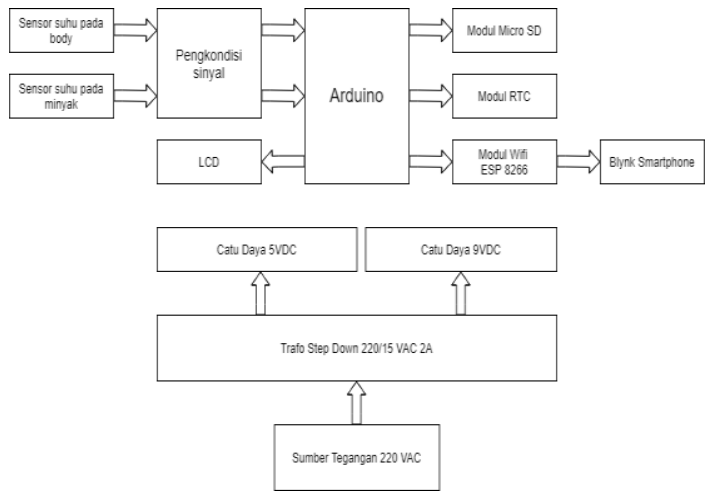

Gambar 1. Blok Diagram Rangkaian

Gambar 1 menunjukkan diagram blok perangkat keras alat. Sumber tegangan PLN 220 VAC digunakan sebagai masukan transformator step down diturunkan menjadi 15 VAC. Tegangan 15 VAC diparalel untuk digunakan sebagai masukan untuk catu daya $9 \mathrm{~V}$ dan 5 V. Catu daya 9 VDC digunakan sebagai suplai arduino yang kemudian arduino akan mensuplai modul RTC DS3231, modul Micro SD dan modul wifi ESP8266 melalui tegangan keluaran 3,3 V dari arduino. Catu daya 5 VDC digunakan sebagai suplai kedua sensor thermocouple dan LCD I2C. Sensor thermocouple digunakan untuk mengukur suhu pada body dan minyak transformator. Untuk pengukuran suhu pada minyak transformator digunakan sensor thermocouple jenis waterproof dan anti korosi. Modul wifi ESP8266 digunakan untuk menghubungkan arduino dengan jaringan internet serta sebagai modul transfer data ke Blynk [8][9][10]. Module RTC DS3231 digunakan sebagai pencatat waktu pada proses data logging. Module Micro SD digunakan untuk mengakses Micro SD sebagai penyimpan data pada proses data logging. Smartphone digunakan untuk memonitor suhu pada minyak transformator dan menampilkan trendline suhu melalui aplikasi Blynk seperti yang ditunjukkan oleh Gambar 5. Adapaun bentuk desain body alat ditunjukkan oleh Gambar 2.

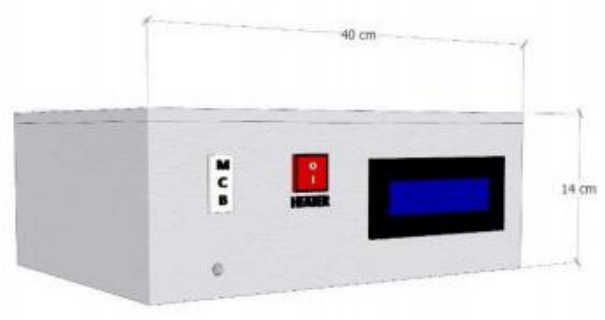

Gambar 2. Desain tampak depan alat

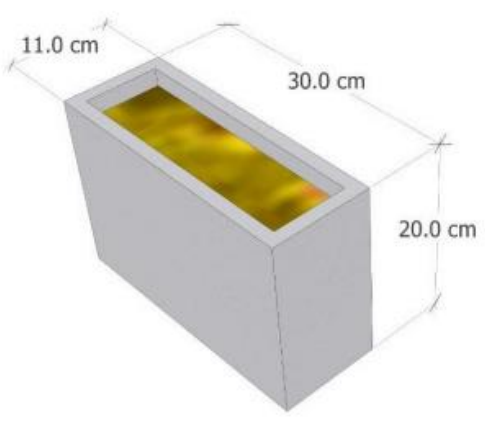

Gambar 3. Bentuk wadah minyak trafo

Gambar 4 menunjukkan diagram alir cara kerja alat. Sensor suhu pada minyak akan membaca suhu awal minyak dan juga sensor suhu pada body akan membaca suhu awal wadah (body trafo) seperti yang ditunjukkan oleh Gambar 3. Heater elektrik akan memanaskan minyak pada wadah sampai kedua suhu steady (tidak berubah). Suhu body dan suhu minyak transformator selama proses pemanasan dari awal sampai steady state akan termuat pada data logger dalam interval 1 detik. Menghitung konstanta pengali untuk mengestimasi suhu minyak melalui suhu body. Didapatkan konstanta pengali dari data kedua suhu dan memasukkan konstanta pengali ke dalam program arduino. Estimasi suhu minyak akan ditampilkan secara real time di aplikasi Blynk.

\section{B. Diagram Alir}

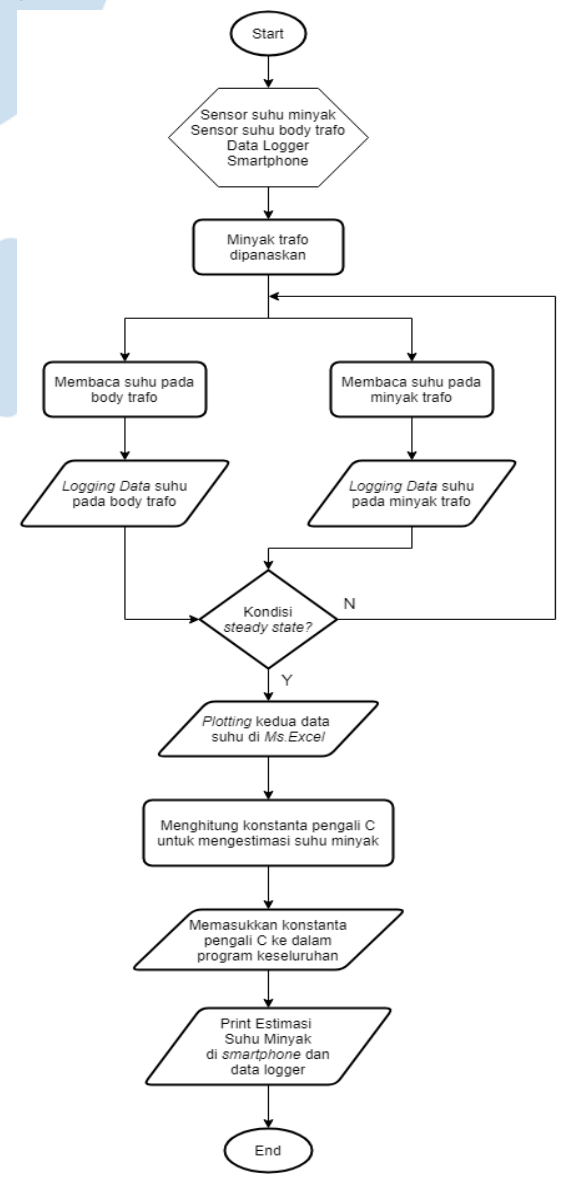

Gambar 4. Diagram Alir 


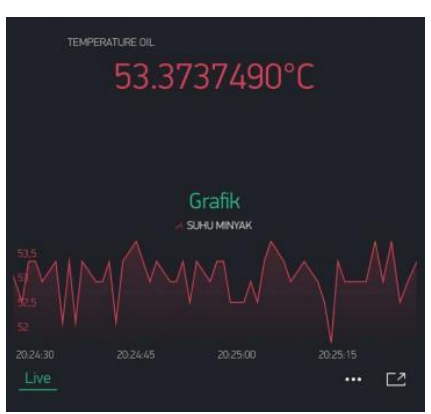

Gambar 5. Bentuk tampilan akusisi temperature minyak pada aplikasi Blynk

\section{PENGUJIAN DAN ANALISIS}

Pengujian dilakukan dengan cara memanaskan minyak pada wadah kemudian mengambil data suhu body dan suhu minyak menggunakan data logger. Minyak dipanaskan sampai suhu minyak dan suhu body steady (tidak lagi terjadi kenaikan suhu). Gambar 6 menunjukkan grafik hasil eksperimen.

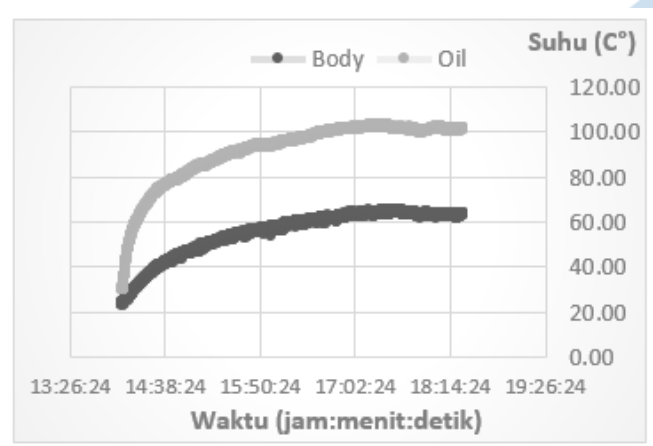

Gambar 6. Grafik kondisi steady suhu body dan oil

Langkah-langkah mengidentifikasi model orde 1 dengan metode ini adalah sebagai berikut [11]:

1. Sistem orde 1

$$
\frac{\mathrm{C}(\mathrm{s})}{\mathrm{R}(\mathrm{s})}=\mathrm{G}(\mathrm{s})=\frac{\mathrm{K}}{\mathrm{Ts}+1}
$$

Transformasi balik Laplace memberikan hasil keluaran dalam fungsi waktu [11]

$$
\mathrm{C}(\mathrm{t})=\mathrm{K}\left(\mathrm{R}(\mathrm{t})-\mathrm{e}^{-\mathrm{t} / \mathrm{T}}\right)
$$

2. Mencari response dengan mengetahui besar input step (dalam kasus ini input step berupa power heater yaitu 90 Watt).

3. Menghitung parameter K (gain)

$\Delta$ oil $=$ Suhu saat steady state - Suhu terendah

$$
\begin{aligned}
& =101-30 \\
& =71
\end{aligned}
$$

$\Delta$ body $=$ Suhu saat steady state - Suhu terendah

$$
\begin{aligned}
& =63-23 \\
& =40
\end{aligned}
$$

$\partial=$ Perubahan magnitude steady state pada input

$$
=90-0
$$$$
=90
$$

$$
\begin{aligned}
\mathrm{K} \text { oil } & =\frac{\Delta}{\partial} \\
& =\frac{71}{90} \\
& =0.78888
\end{aligned}
$$

$\mathrm{K}$ body $=\frac{\Delta}{\partial}$

$$
\begin{aligned}
& =\frac{40}{90} \\
& =0.44444
\end{aligned}
$$

4. Menghitung nilai $63 \% \Delta$

$63 \% \Delta$ oil $=$ Suhu terendah $+0.63 \Delta$

$$
\begin{aligned}
& =30+44.73 \\
& =74.73
\end{aligned}
$$

$63 \% \Delta$ body $=$ Suhu terendah $+0,63 \Delta$

$$
=23+25.2=47.2
$$

5. Menghitung $T$ (time constant) yaitu t saat $63 \% \Delta$

$\mathrm{T}$ oil $=\mathrm{t}$ saat suhu oil 74.73

$$
=1376 \mathrm{~s}
$$

$\mathrm{T}$ body $=\mathrm{t}$ saat suhu body 47.2

$$
=2638 \mathrm{~s}
$$

6. Didapatkan solusi untuk model oil dan body

- Solusi model suhu oil

Suhu oil $(\mathrm{t})=0.788\left(90-\mathrm{e}^{-\mathrm{t} / 1376}\right)$

- Solusi model suhu body

Suhu $\operatorname{body}(\mathrm{t})=0.444\left(90-\mathrm{e}^{-\mathrm{t} / 2638}\right)$

Memeriksa suhu body dan oil terhadap waktu menggunakan model yang didapat. Mencari konstanta pengali $\mathrm{C}$ yang didapat dari hubungan

$$
\begin{aligned}
C & =\frac{\text { Suhu body }}{\text { Suhu oil }} \\
& =\frac{0.788\left(90-\mathrm{e}^{-\mathrm{t} / 1376}\right)}{0.444\left(90-\mathrm{e}^{-\mathrm{t} / 2638}\right)}
\end{aligned}
$$

Pada kondisi steady state maka $\mathrm{e}^{-\mathrm{t} / \mathrm{T}}$ menjadi $\approx 0$. Maka didapatkan :

$$
\begin{aligned}
\mathrm{C} & =\frac{0.788}{0.444} \\
& =1.7749
\end{aligned}
$$

Dikarenakan terlalu banyak data yang termuat dalam proses pengambilan data (12697 detik), berikut beberapa sampel data hasil estimasi suhu minyak melalui pengukuran suhu body menggunakan konstanta pengali $\mathrm{C}$ dalam rentang suhu minyak 40 90 derajat celcius seperti yang ditunjukkan oleh Tabel 1.

Tabel 1. Hasil Estimasi Suhu Minyak

\begin{tabular}{|c|c|c|c|c|}
\hline $\begin{array}{c}\text { Suhu } \\
\text { Body } \\
\left({ }^{\circ} \mathrm{C}\right)\end{array}$ & $\begin{array}{c}\text { Suhu } \\
\text { Oil } \\
\left({ }^{\circ} \mathrm{C}\right)\end{array}$ & $\begin{array}{c}\text { Estimasi } \\
\text { Suhu } \\
\text { Oil }\left({ }^{\circ} \mathrm{C}\right)\end{array}$ & $\begin{array}{c}\text { Selisih }\left({ }^{\circ} \mathrm{C}\right) \\
(\text { Estimasi }- \\
\text { Suhu Oil })\end{array}$ & $\begin{array}{c}\text { Error \% } \\
(\text { Selisih } / \\
\text { Suhu Oil) }\end{array}$ \\
\hline 25.00 & 41 & 44.36 & 3.36 & 8.20 \\
\hline 25.50 & 43.25 & 45.25 & 2.00 & 4.62 \\
\hline 26.00 & 45 & 46.14 & 1.14 & 2.53 \\
\hline 26.50 & 47 & 47.03 & 0.03 & 0.06 \\
\hline 26.50 & 48 & 47.03 & 1.03 & 2.15 \\
\hline 26.75 & 49.5 & 47.47 & 2.03 & 4.10 \\
\hline 27.25 & 50.25 & 48.36 & 1.89 & 3.76 \\
\hline 28.00 & 51.75 & 49.69 & 2.06 & 3.98 \\
\hline 28.25 & 52.75 & 50.13 & 2.65 & 5.02 \\
\hline 29.50 & 55.75 & 52.35 & 3.4 & 6.10 \\
\hline 30.00 & 57 & 53.24 & 3.76 & 6.60 \\
\hline 30.75 & 58.25 & 54.57 & 3.68 & 6.32 \\
\hline 31.00 & 59.25 & 55.02 & 4.23 & 7.14 \\
\hline 31.50 & 60 & 55.91 & 4.09 & 6.82 \\
\hline 32.50 & 61.5 & 57.68 & 3.82 & 6.21 \\
\hline
\end{tabular}




\begin{tabular}{|c|c|c|c|c|}
\hline 32.75 & 62.25 & 58.12 & 4.13 & 6.63 \\
\hline 33.25 & 62.75 & 59.01 & 3.74 & 5.96 \\
\hline 34.25 & 64.75 & 60.79 & 3.96 & 6.12 \\
\hline 34.00 & 64.5 & 60.34 & 4.16 & 6.45 \\
\hline 34.50 & 65 & 61.23 & 3.77 & 5.80 \\
\hline 35.00 & 66 & 62.12 & 3.88 & 5.88 \\
\hline 35.75 & 67.25 & 63.45 & 3.80 & 5.65 \\
\hline 37.00 & 68.25 & 65.67 & 2.58 & 3.78 \\
\hline 37.50 & 69.5 & 66.55 & 2.95 & 4.24 \\
\hline 37.75 & 70.25 & 67.00 & 3.25 & 4.63 \\
\hline 38.25 & 71 & 67.89 & 3.11 & 4.38 \\
\hline 39.25 & 72.25 & 69.66 & 2.59 & 3.58 \\
\hline 40.25 & 73 & 71.43 & 1.57 & 2.15 \\
\hline 41.25 & 74.25 & 73.21 & 1.04 & 1.40 \\
\hline 41.50 & 74.5 & 73.65 & 0.85 & 1.14 \\
\hline 41.00 & 75.25 & 72.77 & 2.48 & 3.30 \\
\hline 42.00 & 76 & 74.54 & 1.46 & 1.92 \\
\hline 42.50 & 77 & 75.43 & 1.57 & 2.04 \\
\hline 43.25 & 77 & 76.76 & 0.24 & 0.31 \\
\hline 43.25 & 77.25 & 76.76 & 0.49 & 0.63 \\
\hline 43.00 & 78 & 76.32 & 1.68 & 2.15 \\
\hline 43.50 & 78 & 77.20 & 0.80 & 1.03 \\
\hline 44.00 & 78.25 & 78.09 & 0.16 & 0.20 \\
\hline 44.25 & 78.5 & 78.53 & 0.03 & 0.04 \\
\hline 44.50 & 79 & 78.98 & 0.02 & 0.03 \\
\hline 44.50 & 79.75 & 78.98 & 0.77 & 0.97 \\
\hline 45.00 & 80 & 79.86 & 0.14 & 0.18 \\
\hline 45.50 & 80.75 & 80.75 & 0.00 & 0.00 \\
\hline 45.75 & 81 & 81.20 & 0.20 & 0.25 \\
\hline 46.00 & 81.75 & 81.64 & 0.11 & 0.13 \\
\hline 46.25 & 82.25 & 82.08 & 0.17 & 0.21 \\
\hline 47.00 & 83 & 83.41 & 0.41 & 0.49 \\
\hline 47.50 & 84 & 84.30 & 0.30 & 0.36 \\
\hline 47.75 & 84.75 & 84.75 & 0.00 & 0.00 \\
\hline 48.00 & 85 & 85.19 & 0.19 & 0.22 \\
\hline 49.50 & 86 & 87.85 & 1.85 & 2.15 \\
\hline 50.00 & 87.25 & 88.74 & 1.49 & 1.71 \\
\hline 50.75 & 88.25 & 90.07 & 1.82 & 2.06 \\
\hline 51.75 & 90.25 & 91.84 & 1.59 & 1.76 \\
\hline Rata - Rata & Error & 1.89 & 3.03 \\
\hline & & & & \\
\hline
\end{tabular}

dengan rata-rata error 0,85 persen. Hal tersebut dikarenakan perhitungan menggunakan konstanta pengali (C) pada kondisi steady state sehingga yang paling mendekati kondisi steady state adalah suhu minyak pada rentang suhu 80 - 90 derajat.

Dari analisa di atas, metode yang telah dijabarkan dalam artikel ini dapat dengan mudah diaplikasikan di lapangan pada transformator existing. Konstanta pengali (C) dapat ditentukan langsung dengan membandingkan suhu steady state minyak pada transformator (indikator oil pada relay thermal) dan suhu pada body transformator. Bilamana konstanta pengali (C) diketahui maka secara praktis suhu minyak dapat diestimasi dari suhu body transformator dengan cara mengalikan langsung konstanta pengali (C) dengan suhu body.

\section{SIMPULAN}

Setelah dilakukan uji kenaikan suhu body dan oil sampai dengan kondisi steady state pada kedua suhu, didapatkan konstanta pengali $(\mathrm{C})=1.7749$. Adapun berdasarkan hasil perhitungan, estimasi suhu minyak efektif/optimal pada rentang suhu 40 - 90 derajat celcius karena kesalahan yg didapat cenderung kecil yaitu dengan rata-rataselisih suhu minyak dengan hasil estimasinya adalah 1.89 derajat celcius. Pada pengujian minyak diatas digunakan wadah yang terbuka yang mana kurang sesuai dengan kondisi aslinya maka dari itu disaranakan untuk melakukan pengujian di transformator tenaga pada gardu induk untuk mengetahui hasil secara langsung (real). Kemudian disarankan juga untk melakukan pengujian dengan menggunakan minyak trafo baru untuk dapat membandingkan hasilnya.

\section{UCAPAN TERIMA KASIH}

Penulis mengucapkan terima kasih kepada Laboratorium Sistem Kontrol, Departemen Teknologi Industri, Sekolah Vokasi Universitas Diponegoro.

\section{DAFTAR PUSTAKA}

Setelah didapatkan hasil pengujian pada rentang suhu minyak 40 - 90 derajat, dapat dijabarkan rata-rata error pada rentang suhu tertentu seperti yang ditunjukkan oelh Tabel 2.

Tabel 2. Rata-rata error pada rentang suhu tertentu

\begin{tabular}{|c|c|}
\hline Rentang Suhu & Rata-rata error $(\%)$ \\
\hline $40-50$ & 3.51 \\
\hline $50-60$ & 6.00 \\
\hline $60-70$ & 5.58 \\
\hline $70-80$ & 1.50 \\
\hline $80-90$ & 0.85 \\
\hline
\end{tabular}

Diketahui bahwa pengukuran suhu minyak menggunakan metode ini memiliki hasil pengukuran yang terbaik pada rentang suhu 80 - 90 derajat celcius

[1] G. F. Fahnani. and M. Karnoto ST, "Transformator daya," Anal. PENGUKURAN DAN PEMELIHARAAN Transform. DAYA PADA, 2011.

[2] I. A. Prastowo, W. Winarso, and A. J. Taufiq, "Analisis Kinerja Sistem Proteksi Transformator Tenaga Berdasarkan Frekuensi Gangguan Di Gardu Induk 150KV Kalibakal," J. Ris. Rekayasa Elektro, 2020, doi: 10.30595/jrre.v1i2.5258.

[3] J. B. Haryanto and Karnoto, "Pemeliharaan Trafo Arus (CT) pada Gardu Induk 150kV PT. PLN (Persero) P3B JB Region Jawa Tengah dan DIY," J. Tek. Elektro, 2011.

[4] D. Nugroho, "Kegagalan Isolasi Minyak Trafo," Media Elektr. ISSN 1979-7451, 2010.

[5] H. Sayogi, "Analisis Mekanisme Kegagalan Isolasi Pada Minyak Trafo Menggunakan Elektroda Berpolaritas Berbeda Pada Jarum - Bidang," Diponegoro Univ., 2011.

[6] S. N. Jha et al., "Measurement techniques and application of electrical properties for nondestructive quality evaluation of foods-a review," Journal of Food Science and Technology. 2011, doi: 10.1007/s13197-011-0263-x. 
[7] W. Y. Kunto Wibowo and A. Syakur, "Analisis karakteristik breakdown voltage pada dielektrik minyak shell diala $\mathrm{b}$ pada suhu 300 C-130 0 C," Dipenogoro Univ., 2011.

[8] Blynk, "Blynk," Startups - IEEE Internet Things, 2015.

[9] Arafat. S.Kom. M.Kom, "Sistem Pengaman Pintu Rumah berbasis Internet of Things ( IoT ) Dengan ESP8266," J. Ilm. Fak. Tek. "Technologia," 2016.
[10]O. Chieochan, A. Saokaew, and E. Boonchieng, "Internet of things (IOT) for smart solar energy: A case study of the smart farm at Maejo University,” 2017, doi 10.1109/ICCAIS.2017.8217588.

[11]K. H. Ang, G. Chong, and Y. Li, "PID control system analysis, design, and technology," IEEE Trans. Control Syst. Technol., 2005, doi: 10.1109/TCST.2005.847331. 